\section{Benzoyl-arginine naphthylamide (BANA) hydrolysis by Treponema denticola and/or Bacteroides gingivalis in periodontal plaques}

\author{
Bretz WA, Lopatin DE, Loesche WJ. Benzoyl-arginine naphthylamide (BANA) \\ hydrolysis by Treponema denticola and/or Bacteroides gingivalis in periodontal \\ plaques. \\ Oral Microbiol Immunol 1990: 5: 275-279.
}

\begin{abstract}
Treponema denticola and Bacteroides gingivalis are among the few recognized species found in periodontal pockets that can hydrolyze the synthetic peptide Nbenzoyl-DL-arginine-2-naphthylamide (BANA). We determined the presence of these periodontal pathogens in BANA-positive and -negative plaque samples through the use of indirect immunofluorescence antibody techniques. Eighteen of 27 diseased sites gave BANA-positive reactions, and 9 gave BANA-negative reactions. $T$. denticola was present in 16 of 18 BANA-positive reactions, whereas $B$. gingivalis was detected in 9 of the 18 BANA-positive reactions. T. denticola was present in 1 and $B$. gingivalis in 2 of the 9 BANA-negative reactions. Neither organism was detected in the 19 healthy sites that were negative for BANA. All measured differences between BANA-positive and BANA-negative plaques obtained in the same individuals were statistically significant. The accuracy of the BANA test, compared with clinical parameters such as bleeding upon probing and increased probing depth, was about $80 \%$. The accuracy of the test in detecting the presence of $T$. denticola was $93 \%$, for $B$. gingivalis, $76 \%$ and for $T$. denticola and/or B. gingivalis, $96 \%$. This study indicated that BANA-positive plaques were associated with the presence of $T$. denticola and/or $B$. gingivalis, that $T$. denticola was found at a greater frequency and levels in BANA-positive plaques than $B$. gingivalis, and that the presence of these organisms was associated with clinical disease.
\end{abstract}

W. A. Bretz, D. E. Lopatin, W. J. Loesche

Department of Biologic and Materials Sciences, School of Dentistry, University of Michigan, Ann Arbor, Michigan, USA

Key words: BANA test; immunofluorescence; Treponema denticola; Bacteroides gingivalis; periodontal plaque

Walter A. Bretz, DDS, MPH, 3204 School of Dentistry, University of Michigan, Ann Arbor, MI 48109-1078, USA

Accepted for publication October 20, 1989
Treponema denticola (a small spirochete) and Bacteroides gingivalis have been strongly associated with periodontal lesions $(7,8,18,19)$. Both organisms produce a number of virulence factors that may play a role in periodontal tissue destruction, which would include collagenase and lipopolysaccharides (3, $8,21)$. Given the importance of these 2 organisms in periodontal disease, rapid and simple assays for monitoring Subgingival plaques for these periodontal pathogens would have great clinical value.

$T$. denticola and $B$. gingivalis are among the few recognized species found in gingival crevices or periodontal pockets that can hydrolyze the synthetic peptide N-benzoyl-DL-arginine-2naphthylamide (BANA) $(4,5)$. It was recently found that Bacteroides forsy- thus also possesses BANA activity (20). BANA hydrolysis by plaque samples has been significantly associated with increasing probing depth and attachment loss and with high levels and proportions of spirochetes (9). It was not possible to associate BANA hydrolysis with $T$. denticola, as this organism cannot be quantitatively recovered from plaque samples by cultural procedures (17). The plaque BANA assay was subsequently shown to be a sensitive and specific screening tool for recognizing untreated and treated sites in periodontal patients (15).

In this investigation, we determined the presence of $T$. denticola and B. gingivalis in BANA-positive or -negative plaque samples, through the use of indirect immunofluorescence techniques employing polyclonal antibodies specif- ic to each organism. Thus, this report focuses on comparisons of BANA hydrolysis with clinical parameters and with the presence and levels of these periodontopathogens in the plaque.

\section{Material and methods}

Subgingival plaque samples $(2-4$ sites per patient) were collected by means of a sterile curette from 17 untreated adult periodontitis patients with no history of antibiotic usage in the past 6 months. A total of 46 samples were collected from 27 diseased sites and 19 healthy sites. The supragingival plaque was removed and discarded, and subgingival specimens were inoculated into a vial containing $0.2 \mathrm{ml}$ of Sorensen phosphate buffer (pH 7.2) and dispersed for $20 \mathrm{~s}$ 
utilizing a vortex mixer (working suspension).

\section{Dark-field microscopy}

Ten microliters of the working suspension was placed on a glass slide, covered with a cover slip, sealed, and examined under a dark-field microscope. The total number of bacteria per high-power microscopic field (HPF) and the total number of spirochetes/HPF (which were further subdivided into small, intermediate and large spirochetes) were obtained by counting 200 organisms or the number of organisms in $20 \mathrm{HPF}$, whichever event occurred first.

\section{BANA assay}

One hundred microliters of the synthetic substrate n-benzoyl-DL-arginine-2naphthylamide (BANA), previously diluted $(10 \mu \mathrm{l}$ of $44 \mathrm{mg}$ BANA/ml in DMSO, in $1 \mathrm{ml}$ Sorensen buffer), was added to $100 \mu \mathrm{l}$ of the working suspension and incubated in aerobic conditions $\left(37^{\circ} \mathrm{C}\right)$ for an average of $18 \mathrm{~h}$.
The BANA test results were read visually using scoring procedures described elsewhere (1). Separate studies using pure cultures of B. gingivalis and T. denticola demonstrated that weak-positive results contained about $5 \times 10^{5}$ colonyforming units (CFU) of $B$. gingivalis and $1 \times 10^{6} \mathrm{CFU}$ of $T$. denticola (10). For purposes of statistical analysis, weakpositive and positive results were grouped as positive results.

\section{Indirect immunofluorescence assay}

The remaining plaque suspension (90 $\mu \mathrm{l})$ was added to an equal volume of $1 \%$ formaldehyde, yielding a final concentration in the reaction mixture of $0.5 \%$ formaldehyde, and stored at $4{ }^{\circ} \mathrm{C}$ for further analysis.

Ten microliters of the formaldehydefixed subgingival plaque samples was applied to a 12-well microscope slide, heat-fixed and Gram-stained. These counts provided total bacterial counts per HPF. Subsequently, $10 \mu \mathrm{l}$ of the plaque samples was applied to a second 12-well slide, heat-fixed and stored at

Table 1. Cross-reaction between selected antibacterial antibodies

\begin{tabular}{|c|c|c|}
\hline \multirow[b]{2}{*}{ Bacteria } & \multicolumn{2}{|c|}{ Polyclonal antibody (1/1000 titer) } \\
\hline & $\begin{array}{l}\text { T. denticola } \\
\text { (ATCC 35405) }\end{array}$ & $\begin{array}{l}\text { B. gingivalis } \\
\text { (ATCC 33277) }\end{array}$ \\
\hline $\begin{array}{l}\text { Actinomyces viscosus } \\
\text { (human isolates) }\end{array}$ & $0^{\mathrm{a}}$ & 0 \\
\hline $\begin{array}{l}\text { Fusobacterium nucleatum } \\
\text { (human isolates) }\end{array}$ & 0 & 0 \\
\hline $\begin{array}{l}\text { Streptococcus sanguis } \\
\text { (ATCC 10556) }\end{array}$ & 0 & 0 \\
\hline $\begin{array}{l}\text { Selenomonas sputigena } \\
\text { (human isolates) }\end{array}$ & 0 & 0 \\
\hline Actinobacillus actinomycetemcomitans (Y4) & 0 & 0 \\
\hline $\begin{array}{l}\text { Bacteroides gingivalis } \\
\text { (ATCC 33277) }\end{array}$ & 0 & +4 \\
\hline $\begin{array}{l}\text { Bacteroides gingivalis } \\
\text { (human isolates) }\end{array}$ & ND & +4 \\
\hline $\begin{array}{l}\text { Bacteroides intermedius } \\
\text { (human isolates) }\end{array}$ & ND & 0 \\
\hline Bacteroides melaninogenicus & & 0 \\
\hline $\begin{array}{l}\text { (human isolates) } \\
\text { Capnocytophaga ochraceus }\end{array}$ & ND & 0 \\
\hline $\begin{array}{l}\text { (human isolates) } \\
\text { Treponema denticola }\end{array}$ & ND & 0 \\
\hline $\begin{array}{l}\text { (ATCC } 35405 \text { ) } \\
\text { Treponema vincentii }\end{array}$ & +4 & 0 \\
\hline $\begin{array}{l}\text { (ATCC } 35580) \\
\text { Treponema socranskii }\end{array}$ & +2 & 0 \\
\hline $\begin{array}{l}\text { (ATCC 35536) } \\
\text { Unspeciated }\end{array}$ & +2 & 0 \\
\hline Treponema & +2 & 0 \\
\hline
\end{tabular}

${ }^{a}$ Characteristics of positive cells: +4 : brilliant fluorescence with good definition of cell wall, dark center; +3 : moderate fluorescence with good definition of cell wall, dark center; +2 ; faint fluorescence with poor definition of cell wall; +1 : barely detectable fluorescence, single cells not distinguishable; 0 : no detectable fluorescence. $\mathrm{ND}=$ not done.

room temperature. Two wells were used for a positive control (pure bacterial culture + antibody + fluorescein isothiocyanide (FITC)-conjugate) and a negative control (pure bacterial culture + buffer + FITC-conjugate).

The plaque samples were stained for $10 \mathrm{~min}$ with $10 \mu \mathrm{l}$ of antisera diluted to working titers in PBS containing $0.05 \%$ Tween 20, washed in phosphate-buffered saline (PBS) and rinsed with distilled water. The slides were then incubated with $10 \mu \mathrm{l}$ of goat anti-rabbit IgG conjugated with FITC. Slides were again rinsed and washed, and subsequently mounted with glycerol in PBS $(2: 1 \mathrm{v} / \mathrm{v})$ containing paraphenylenediamine ( $\mathrm{pH} 9.0)$, sealed with a cover slip and nail polish.

Immunofluorescence was evaluated with a Leitz Dialux microscope equipped with a Ploempak 2.3 fluorescence illuminator for epifluorescence. The light source was a 200-W HBO mercury superpressure lamp. Fluorescence was graded from 0 to $4+$, with grades $3+$ and $4+$ considered serologically positive reactions. Staining was considered positive for the selected microorganism(s) if it exhibited strong fluorescent cells with well defined outlines and dark or lightly shining centers, comprising more than $1 \%$ of the total cell count. Data were calculated as positive cells per HPF. The antibodies used only stained cells with a spirochetal morphology in the case of the $T$. denticola antibody, or cells with a cocco-bacilli morphology in the case of the B. gingivalis antibody, thereby indicating the species specificity of these antibodies.

\section{Antibodies}

American Type Culture Collection (ATCC) reference strains of $B$. gingivalis (ATCC 33277) and T. denticola (ATCC 35405) were grown as previously described $(12,14)$. The cultures were grown under anaerobic conditions $\left(85 \% \quad \mathrm{~N}_{2}, 10 \% \mathrm{H}_{2}\right.$, and $\left.5 \% \mathrm{CO}_{2}\right)$ at $35^{\circ} \mathrm{C}$ until maximum turbidity was reached (about 3 to $5 \mathrm{~d}$ ). The bacteria were harvested by centrifugation and washed 3 times in $0.15 \mathrm{M} \mathrm{NaCl}$. The cells were then resuspended in $1 \%$ formaldehyde in PBS and stored at $4{ }^{\circ} \mathrm{C}$ for $4 \mathrm{~d}$. The cells were then washed 3 times in PBS to remove formaldehyde and lyophilized.

High-titer polyclonal rabbit antibodies were prepared by subcutaneous immunization of female New Zealand 
Table 2. Frequency distribution of clinical status, BANA hydrolysis and presence of $T$. denticola and/or $B$. gingivalis in subgingival plaque samples

\begin{tabular}{|c|c|c|c|c|}
\hline \multirow[b]{2}{*}{ Presence of species in plaque } & \multicolumn{2}{|c|}{$\begin{array}{l}\text { Diseased }(n=27) \\
\text { BANA hydrolysis }\end{array}$} & \multicolumn{2}{|c|}{$\begin{array}{l}\text { Healthy }(n=19) \\
\text { BANA hydrolysis }\end{array}$} \\
\hline & $\begin{array}{c}\text { positive } \\
n=18\end{array}$ & $\begin{array}{c}\text { negative } \\
n=9\end{array}$ & $\begin{array}{c}\text { positive } \\
n=0\end{array}$ & $\begin{array}{c}\text { negative } \\
n=19\end{array}$ \\
\hline \multicolumn{5}{|l|}{ Treponema denticola } \\
\hline yes & 16 & 1 & 0 & 0 \\
\hline no & 2 & 8 & 0 & 19 \\
\hline \multicolumn{5}{|l|}{ Bacteroides gingivalis } \\
\hline yes & 9 & 2 & 0 & 0 \\
\hline no & 9 & 7 & 0 & 19 \\
\hline Either present & 18 & 2 & 0 & 0 \\
\hline Both absent & 0 & 7 & 0 & 19 \\
\hline
\end{tabular}

white rabbits with $2 \mathrm{mg}$ of the lyophilized immunization antigen in complete Freund's adjuvant at 0 and 1 week, followed by booster immunization in incomplete Freund's adjuvant at 7 weeks following first immunization. Pre-immune and immune (post 7 weeks) bleedings were obtained and antibody titers determined. All sera were aliquotted and frozen.

\section{Clinical parameters of periodontal sites}

Diseased $(n=27)$ or healthy $(n=19)$ periodontal sites were identified based on bleeding upon probing (yes or no), probing depth measurements, and the clinical judgement of whether or not that periodontal site should undergo periodontal treatment beyond that associated with a routine dental cleaning by a hygienist.

\section{Statistical analysis}

Frequency tables, 4-fold tables and paired $t$-tests were calculated using the SAS computer program (SAS Institute, Cary, NC).

Table 3. Mean (average $\pm \mathrm{SD}$ ) differences between BANA-positive and BANA-negative plaques

\begin{tabular}{lccc}
\hline & $\begin{array}{c}\text { BANA-positive } \\
(n=11)\end{array}$ & $\begin{array}{c}\text { BANA-negative } \\
(n=11)\end{array}$ & $\begin{array}{c}P \\
\text { (paired } t \text {-test) }\end{array}$ \\
\hline Immunofluorescence & & & \\
$\quad$ Treponema denticola & $21.0 \pm 28.6^{\mathrm{a}}$ & $0.0 \pm 0.0$ & $<0.034$ \\
$\quad$ Bacteroides gingivalis & $3.0 \pm 3.0$ & $0.3 \pm 0.6$ & $<0.010$ \\
Dark-field microscopy & & & \\
$\quad$ Total bacteria & $18.8 \pm 13.8$ & $5.3 \pm 4.8$ & $<0.017$ \\
Total spirochetes & $6.0 \pm 4.7$ & $0.1 \pm 0.3$ & $<0.001$ \\
Small spirochetes & $2.8 \pm 1.8$ & $0.02 \pm 0.03$ & $<0.001$ \\
Intermediate spirochetes & $1.8 \pm 1.5$ & $0.06 \pm 0.1$ & $<0.002$ \\
$\quad$ Large spirochetes & $1.3 \pm 1.5$ & $0.05 \pm 0.1$ & $<0.018$ \\
Clinical & & & $<0.001$ \\
$\quad$ Probing depth & $6.5 \pm 1.9$ & $2.6 \pm 0.9$ & \\
\hline
\end{tabular}

\footnotetext{
average \pm SD.
}

had probing depths $\geq 4 \mathrm{~mm}$. Table 2 shows the frequency of diseased and healthy sites, BANA hydrolysis and immunologic detection of $T$. denticola and or $B$. gingivalis in the plaque samples. Eighteen of 27 plaques from diseased sites gave BANA-positive plaques, and 9 plaques from diseased sites gave BANA-negative plaques. Indirect immunofluorescence analysis revealed $T$. denticola in 16 of 18 BANA-positive plaques and $B$. gingivalis in 9 of 18 BANA-positive plaques. $T$. denticola and $B$. gingivalis were present in 1 and 2 (respectively) of the 9 BANA-negative plaques. All 19 healthy sites were negative for BANA and T. denticola and/or $B$. gingivalis were not detected.

All measured differences between BANA-positive and BANA-negative plaques obtained in the same individuals were statistically significant (Table 3). BANA-positive plaques harbored $T$. denticola at levels of 21 cells/HPF, whereas $B$. gingivalis was detected at levels of 3 cells/HPF. Similarly, total number of bacteria/HPF as well as the levels of spirochetes as counted by darkfield microscopy were significantly different between BANA-positive and BANA-negative plaques. BANA-positive reactions were associated with plaques taken from pockets $6.5 \mathrm{~mm}$ deep on average, whereas BANA-negative results were associated with plaques taken from shallow pocketes of $2.6 \mathrm{~mm}$ on average.

The sensitivity and specificity of the BANA test reaction measured against the clinical parameters is shown in Table 4 . One would be interested in determining the overall ability of the test, to distinguish between diseased and healthy sites. This can be derived by the sum of true positives plus true negatives divided by the total number of comparisons (accuracy). When the BANA test was measured against the subjectively determined clinical parameters, the accuracy of the BANA test was about $80 \%$ (Table 4). The accuracy of the BANA test in terms of detecting the presence of species in plaques (objectively measured parameters) was $93 \%$ for $T$. denticola, $76 \%$ for B. gingivalis and $96 \%$ for T. denticola and/or B. gingivalis (Table 5).

\section{Discussion}

Several studies have associated B. gingivalis with periodontal disease status $(7,18,19,22)$ and a few have associated 
Table 4. Relationship between BANA test and clinical parameters

\begin{tabular}{lcccc}
\hline & & $\begin{array}{c}\text { Clinical } \\
\text { judgement }\end{array}$ & $\begin{array}{c}\text { Bleeding upon } \\
\text { probing }^{\mathrm{b}}\end{array}$ & $\begin{array}{c}\text { Probing }^{\mathrm{a}} \\
\text { depth }^{\mathrm{c}}\end{array}$ \\
\hline Sensitivity & $(++)$ & 66.7 & 64.0 & 66.7 \\
Specificity & $(--)$ & 100.0 & 90.5 & 100.0 \\
False $(-)$ & $(-+)$ & 33.3 & 36.0 & 33.3 \\
False $(+)$ & $(+-)$ & 0.0 & 9.5 & 0.0 \\
Accuracy & $(++)+(--) / \mathrm{T}$ & 80.0 & 76.1 & 80.0 \\
\hline
\end{tabular}

$(++)=$ BANA test positive; clinical parameter positive. $(--)=$ BANA test negative; clinical parameter negative. $(-+)=$ BANA test negative; clinical parameter positive. $(+-)=$ BANA positive; clinical parameter negative. $\mathrm{T}=$ total number of observations. ${ }^{a}{ }^{\text {The judgement of a }}$ healthy versus diseased site based on probing depth and bleeding on probing. ${ }^{b}$ Bleeding upon probing: yes $=$ positive; no $=$ negative.${ }^{\mathrm{c}}$ Probing depth: $\leq 3 \mathrm{~mm}=$ negative; $\geq 4 \mathrm{~mm}=$ positive .

Table 5. Relationship between BANA test and $T$. denticola and/or $B$. gingivalis

\begin{tabular}{lcccc}
\hline & & & & $\begin{array}{c}\text { T. denticola } \\
\text { and/or }\end{array}$ \\
& & T. denticola & B. gingivalis & B. gingivalis \\
\hline Sensitivity & $(++)$ & 94.1 & 81.9 & 90.0 \\
Specificity & $(--)$ & 93.1 & 74.2 & 100.0 \\
False (-) & $(-+)$ & 5.9 & 18.1 & 10.0 \\
False (+) & $(+-)$ & 6.9 & 25.8 & 0.0 \\
Accuracy & $(++)+(--) / T$ & 93.4 & 76.0 & 95.7 \\
\hline
\end{tabular}

$(++)=$ BANA test positive; $T$. denticola and/or $B$. gingivalis positive. $(--)=$ BANA test negative; $T$. denticola and/or $B$. gingivalis negative. $(-+)=$ BANA test negative; $T$. denticola and/or $B$. gingivalis positive. $(+-)=$ BANA test positive; $T$. denticola and/or $B$. gingivalis negative. $\mathrm{T}=$ total number of observations.

T. denticola $(13,16)$. This study, however, is the first to use immunofluorescence analysis to associate the frequency and the levels of both $T$. dentico$l a$ and $B$. gingivalis in subgingival plaque samples with periodontal health or disease. Both organisms were present in BANA-positive plaques of periodontally diseased sites, were detected at a low frequency in BANA-negative plaques removed from diseased sites, and were absent from healthy sites that were uniformly BANA-negative (Table 2). The frequency of occurrence of $T$. denticola in BANA-positive plaques was approximately 2 -fold higher than that of B. gingivalis (Table 2) and the levels of $T$. denticola in BANA-positive plaques were greater than the levels of $B$. gingivalis (Table 3 ).

The accuracy of the BANA test $v s$ clinical parameters never exceeded $80 \%$ (Table 4), perhaps indicating the subjective nature of the clinical parameters, which are affected by measurement error and examiner variability (6). In this respect, the BANA test may be a more objective measure of identifying periodontal sites potentially at risk for developing periodontal destruction through the detection of periodontal pathogens, such as $T$. denticola, $B$. gingivalis and Bacteroides forsythus. Alter- nately, the failure to obtain $100 \%$ accuracy with the clinical parameters could indicate that, in some plaques, bacteria other than $T$. denticola and/or $B$. gingivalis were associated with clinical disease.

The accuracy of the BANA test in detecting $T$. denticola and/or B. gingivalis was about $96 \%$ (Table 5), which means that the BANA test gives information that is as reliable as the information obtained with the immunologic reagents. Given the fact that $T$. denticola cannot be quantified by cultural methods (17), the BANA test could then be considered as a substitute for both cultural and immunologic methods for detecting $T$. denticola and possibly $B$. gingivalis in plaque samples.

The BANA test can detect $T$. dentico$l a$ and $B$. gingivalis when $10^{5}$ to $10^{6} \mathrm{CFU}$ are present in plaque samples (10). These detection limits make the BANA test less sensitive than other methods, such as DNA probes and cultural procedures, which can detect $10^{2}$ to $10^{3}$ CFU. If clinical disease is preceded by or associated with an overgrowth of these periodontal pathogens in plaque samples, then a less sensitive test may be more indicative of an infection that puts periodontal sites at risk for developing periodontal disease.
Several methods, such as cultural, microscopic examination, immunologic reagents, enzyme activity, and DNA probes, could help the clinician monitor plaques for the presence of periodontal pathogens in conjunction with clinical parameters. The BANA test offers the potential to identify plaques that may harbor $T$. denticola, $B$. gingivalis and a third organism, B. forsythus, which has recently been associated with the progressing periodontal lesion (2). The BANA test would then be a simple method of detecting periodontal anaerobic infections.

In summary, this study has indicated that: BANA-positive plaques are associated with the presence of $T$. denticola and/or $B$. gingivalis; $T$. denticola was found at greater frequency and levels in BANA-positive plaques than was $B$. gingivalis; and the presence of the organisms is associated with clinical inflammation in deep periodontal pockets. A BANA test in a solid state that can be performed at chairside has been recently evaluated and shows an accuracy of $84 \%$ with B. gingivalis and T. denticola (11).

\section{Acknowledgements}

This research was supported by grant No. DE02731 from the National Institute of Dental Research and by a gift from Oral-B Laboratories, Redwood City, CA.

\section{References}

1. Bretz WA, Loesche WJ. Characteristics of trypsin-like reaction in subgingival plaque samples. J Dent Res 1987: 66: 1668-1672.

2. Dzink JL, Socransky SS, Haffajee AD. The predominant cultivable microbiota of active and inactive lesions of destructive periodontal diseases. J Clin Periodontol 1988: 15: 316-323.

3. Larjava H, Uitto VJ, Eerola E, Haapasalo $\mathrm{M}$. Inhibition of gingival fibroblast growth by Bacteroides gingivalis. Infect Immun 1987: 55: 201-205.

4. Laughon BE, Syed SA, Loesche WJ Rapid identification of Bacteroides gingivalis. J Clin Microbiol 1982: 15 345-346.

5. Laughon BE, Syed SA, Loesche WJ. API-ZYM system for identification of Bacteroides sp., Capnocytophaga sp. and spirochetes of oral origin. J Clin $\mathrm{Micro}^{-}$ biol 1982: 15: 97-102.

6. Listgarten MA. Periodontal probing. what does it mean? J Clin Periodonto 1980: 7: 165-176. 
7. Loesche WJ, Syed SA, Schmidt E, Morrison EC. Bacterial profiles of subgingival plaques in periodontitis. J Periodontol 1985: 56: 447-456.

8. Loesche WJ. The role of spirochetes in periodontal disease. Adv Dent Res 1988: 2: 275-283.

9. Loesche WJ, Syed SA, Stoll J. Trypsinlike activity in subgingival plaque: a diagnostic marker for spirochetes and periodontal disease? J Periodontol 1987: 58: $266-273$.

10. Loesche WJ, Hujoel P. Microbiologicalbased diagnostic tests for periodontitis. Considerations in regard to sensitivity, specificity and accuracy. The Royal Society of Medicine Symposium: Markers of Disease Susceptibility and Activity for Periodontal Diseases. Cambridge: Cambridge University Press, in press.

11. Loesche WJ, Bretz WA, Lopatin DE et al. Multi-center clinical evaluation of a chairside method for detecting certain periodontopathic bacteria in periodontal disease. J Periodontol 1990: 61: 189-196.

12. Mangan DF, Laughon BE, Bower B, Lopatin DE. In vitro lymphocyte blasto- genic responses and titers of humoral antibodies from periodontitis patients to oral spirochete isolates. Infect Immun 1982: 37: 445-451.

13. Moore WEC, Holdeman LV, Cato EP et al. Comparative bacteriology of juvenile periodontitis. Infect Immun 1985: 48: 507-519.

14. Ohta K, Makinen KK, Loesche WJ. Purification and characterization of an enzyme from $T$. denticola capable of hydrolyzing synthetic trypsin substrates. Infect Immun 1986: 53: 213-220.

15. Schmidt EF, Bretz WA, Hutchinson RA, Loesche WJ. Correlation of the hydrolysis of benzoyl-arginine naphthylamide (BANA) by plaque with clinical parameters and subgingival levels of spirochetes in periodontal patients. J Dent Res 1988: 67: 1505-1509.

16. Simonson LG, Goodman CH, Bial JJ, Morton HE. Quantitative relationship of Treponema denticola to severity of periodontal disease. Infect Immun 1988: 56: $447-456$.

17. Salvador SL, Syed SA, Loesche WJ. Comparison of three dispersion procedures for quantitative recovery of cul- tivable species of subgingival spirochetes. J Clin Microbiol 1987: 25: 2230-2232.

18. Slots J, Listgarten MA. Bacteroides gingivalis, Bacteroides intermedius and Actinobacillus actinomycetemcomitans in human periodontal diseases. J Clin Periodontol 1988: 15: 85-93.

19. Tanner ACR, Socransky SS, Goodson JM. Microbiota of periodontal pockets losing crestal alveolar bone. J Periodont Res 1984: 19: 279.

20. Tanner ACR, Ebersole JL, Listgarten MA, Strzempko MN. Bacteroides forsythus sp. nov., a slow-growing fusiform Bacteroides sp. from the human oral cavity. Int J Syst Bacteriol 1986: 36: 213-221.

21. Uitto VJ, Larjava H, Heino J, Sorsa T. A protease of Bacteroides gingivalis degrades cell surface and matrix glycoproteins of cultural gingival fibroblasts and induces secretion of collagenase and plasminogens activators. Infect Immun 1989: 57: 213-218.

22. Zambon JJ, Reynolds HS, Slots J. Blackpigmented Bacteroides spp. in the human oral cavity. Infect Immun 1981: 32: 198-203. 
This document is a scanned copy of a printed document. No warranty is given about the accuracy of the copy. Users should refer to the original published version of the material. 